\title{
Fate simulation and risk assessment of TBT and TPhT considering water level fluctuations in the TGR before and after AFS Convention implementation in China
}

Jun-min Gao ( $\nabla$ gao-junmin@126.com )

Chongqing University https://orcid.org/0000-0002-7883-8191

Ping-ting Fu

Chongqing University

Xiao-ling Chen

Chongqing University

Jin-song Guo

Chongqing University

Xian-yu Hou

Chongqing University

Jie Zeng

Chongqing University

Zhu-man Chen

Chongqing University

\section{Research}

Keywords: Tributyltin, Triphenyltin, The AFS Convention, Fate simulation, Risk assessment

Posted Date: January 23rd, 2020

DOI: https://doi.org/10.21203/rs.2.18462/v2

License: (c) (1) This work is licensed under a Creative Commons Attribution 4.0 International License. Read Full License

Version of Record: A version of this preprint was published at Environmental Sciences Europe on February 10th, 2020. See the published version at https://doi.org/10.1186/s12302-020-0298-6. 


\section{Abstract}

Background: The Three Gorges Reservoir (TGR) is the largest freshwater reservoir in China. Previous studies showed that organotin pollution is present in the TGR. In June 2011, the AFS Convention went into effect in China. In order to explore the pollution evolution processes of tributyltin (TBT) and triphenyltin (TPhT) before and after implementation of the AFS Convention and their variations with water level fluctuations in the TGR, the characteristic parameters of the TGR and the physicochemical parameters of TBT and TPhT were used to develop a level IV multimedia fugacity model considering water level fluctuations to simulate the fate, transfer, and transport of TBT and TPhT in the TGR. Based on the simulation results, exposure concentrations of TBT and TPhT were then used to assess the ecological and health risks in the TGR region (TGRR).

Results: The simulation results showed that the average concentrations of both TBT and TPhT decreased in all compartments except the sediment, whereas the total content of the system continued to increase after the AFS Convention was implemented. The concentration of TBT in the sediment was higher than that in fish, while the concentration of TPhT in fish was much greater than that in the sediment. The total contents of both TBT and TPhT were highest in the sediment phase. In addition, variations in water level of the TGR significantly affected the distribution and transport of TBT and TPhT in the TGR.

Conclusions: Sediment is an important source and sink of TBT and TPhT, and the water level regulation of the TGR strengthened the two roles of sediment. Both TBT and TPhT in surface water, but especially TBT, carried significant chronic exposure risks to the aquatic community of the TGR. Intake of TPhT, mainly through eating fish, posed a potential health risk to the population in the TGRR.

\section{Background}

Tributyltin (TBT) and triphenyltin (TPhT) are the only two organometallic compounds among the 67 endocrine-disrupting chemicals listed by the US Environmental Protection Agency, and are the most toxic chemicals artificially discharged into aquatic environments. Since the 1960s, the global production and use of organotins (OTs), particularly TBT and TPhT, has significantly increased (Batista-Andrade et al., 2018; Finnegan et al., 2018). Because of their bactericidal properties, TBT and TPhT are widely used as antifouling agents, wood preservatives, fungicides, and pesticides (Anastasiou et al., 2016; Chen et al., 2019). Previous studies have shown that TBT and TPhT can accumulate in some aquatic organisms and cause cumulative poisoning or imposex (Antizar-Ladislao, 2008; Negri and Marshall, 2009), eventually leading to reproductive disorders, population decline, and potential species extinction (Santos et al., 2006; Sun et al., 2011; Zhang et al., 2008). In humans, exposure to OTs may induce cell immunotoxicity, neurotoxicity, mutagenicity, and carcinogenicity, resulting in reproductive and immunological diseases (Kotake, 2012; Yamada et al., 2016). Because of the harmful effects of TBT and TPhT on aquatic organisms and human health, many countries and international organisations have developed water quality criteria and restricted the uses of TBT and TPhT (Sonak et al., 2009). The International Convention on the Control of Harmful Anti-fouling Systems on Ships (AFS Convention) was adopted by 
the International Maritime Organization in 2008 and officially went into effect on June 7, 2011, in China. However, TPhT remains widely used agriculturally in China, except in Taiwan, which banned the use of TPhT pesticides in 1999 (Meng et al., 2009).

The Three Gorges Project is the largest water management project in the world, and the Three Gorges Reservoir (TGR) is the largest freshwater reservoir in China. The TGR provides a habitat for aquatic organisms and a drinking water source for the TGR region (TGRR). After the TGR was created, the hydrologic regimes of the Yangtze River and its tributaries in the reservoir region changed markedly compared with those of the original rivers. The water level of the reservoir alternates between 145 and 175 meters on an annual cycle, with periodic fluctuations that are opposite to the seasonal fluctuations of natural rivers. The flow rate and silt concentration in the reservoir also regularly vary with the water level. Thus, the TGR has characteristics of both rivers and lakes, and pollutants in the water column are periodically mixed, suspended, and sunk; the resulting environmental behaviours of pollutants are more complicated than those in rivers or lakes. In addition, the navigation conditions differ based on water levels in the TGR, which may strongly impact the release of OTs. Although China has implemented the AFS Convention, there remain some small and old ships with OT antifouling paints used in rivers, and other sources of TBT and TPhT may be present. Moreover, TBT and TPhT are stable in sediments and their half-lives range from several months to several decades (Ye et al., 2013). Dredging, eddy currents, and benthic disturbances may cause sediment to be resuspended, and resuspended sediments can act as a source of OTs in water. Previous studies have shown that OT pollution is found in various environmental media (such as water, suspended matter, and sediment) in the TGR. The highest concentration of TBT observed in the water column of the TGR thus far is $393.35 \mathrm{ng} \mathrm{Sn} / \mathrm{L}$ (Gao et al., 2017), and the highest concentration of TPhT is $37.2 \mathrm{ng} \mathrm{Sn/L} \mathrm{(Gao} \mathrm{et} \mathrm{al.,} \mathrm{2013);} \mathrm{both} \mathrm{concentrations} \mathrm{are}$ sufficient to pose significant ecological risks to aquatic organisms in the TGR. Thus, OT pollution in the TGR after implementation of the AFS Convention requires further study.

However, field monitoring and tracking investigations are time-consuming and costly, and can only represent limited pollution circumstances at a given time; therefore, it is difficult to assess the pollution level of the overall aquatic environment. The environmental multimedia model offers a simple and economical method to describe the environmental behaviours of chemical substances in various media (Dale et al., 2015; Di Guardo et al., 2018). Therefore, environmental multimedia modelling, particularly involving the fugacity approach, is widely used for chemical risk assessment and fate simulation studies, such as fate simulation of antibiotics in seasonal glacial rivers (Sun et al., 2019), fate evaluation of polycyclic aromatic hydrocarbons in the Songhua River (Wang et al., 2012), and the fate and transport of spilled oil in the Arctic region (Arzaghi et al., 2018). Although Ranke (2002) used a simple water-sediment multimedia model to simulate the persistence of TBT antifouling paint in the ocean, few other studies have investigated OTs using the environmental multimedia model, especially in a complicated aquatic environment such as the TGR.

Therefore, this study combined characteristics of the ecological environment and hydrological changes in the TGR to establish a Level IV multimedia fugacity model of TBT and TPhT, in order to explore the fate, 
transfer, and transport of TBT and TPhT in different media of the aquatic environment based on water level fluctuations; it then assessed risks to aquatic organisms and humans in the TGRR before and after the AFS Convention was implemented in China. The results of this study can be used to evaluate the effectiveness of the implementation of the AFS Convention, provide a scientific basis for OT management and risk assessment, and offer new insights into the environmental behaviours of endocrine disruptors in deep-channel reservoir systems that experience water level fluctuations.

\section{Materials And Methods}

\subsection{Study area}

The study area (Fig. 1(a)), the TGRR, is located between $29^{\circ} 16^{\prime} \sim 31^{\circ} 25^{\prime} \mathrm{N}$ and $106^{\circ} 0^{\prime} \sim 111^{\circ} 50^{\prime} \mathrm{E}$. The reservoir has more than 30 tributaries, a length of approximately $660 \mathrm{~km}$, and an average width of approximately $1100 \mathrm{~m}$. From 2003 to 2008, the TGR experienced water levels of $135 \mathrm{~m}, 156 \mathrm{~m}, 172 \mathrm{~m}$ and $175 \mathrm{~m}$ in the storage stage. Since 2008, the water level of the reservoir has periodically fluctuated between 145 and $175 \mathrm{~m}$ (Fig. 1(b)) to meet the needs of flood control and power generation in a pattern that is opposite to the seasonal fluctuations of natural rivers. After storage began in the reservoir, the flow velocity of the main river decreased from $2 \mathrm{~m} / \mathrm{s}$ to $0.25-0.50 \mathrm{~m} / \mathrm{s}$, while that of the tributaries was reduced to $0.006 \mathrm{~m} / \mathrm{s}$. The average annual temperature in the TGRR is approximately $16.6^{\circ} \mathrm{C}$ and the annual average rainfall of $1124.5 \mathrm{~mm}$ occurs mainly from April to October; this period contributes $80 \%$ of total annual precipitation (Xu et al., 2009).

\subsection{Level IV multimedia fugacity model with water level fluctuations in the TGR}

\subsubsection{Model development}

The model used in this study was based on the QWASI model developed by the Canadian Environmental Modelling Centre (Mackay and Hickie, 2000). Four bulk compartments (phases) were considered, including atmosphere, water, sediment, and fish. Each bulk compartment contains sub-compartments. The atmosphere consists of air and aerosols; water consists of water and suspended solids; sediment contains solids and pore water; for simplicity, the biota compartment is represented by fish. Four types of environmental behaviours, including water advection, emission, degradation, and intermedia transfer, were regarded as the main processes affecting TBT and TPhT in the aquatic environment of the TGR, as shown in Fig. 2.

The model assumed that TBT and TPhT were in a homogeneous, unsteady, and non-equilibrium state in all four bulk compartments. Based on the level IV fugacity approach and mass balance, differential equations were established as follows

See equations $1-4$ in the supplemental files. 
where

$\mathrm{t}$-simulation time $(\mathrm{h}) \rrbracket$

A, W, S, F-atmosphere, water, sediment, fish;

$V_{i}(i=A, W, S, F)$-the volume of each bulk compartment $\left(m^{3}\right)$;

$\mathrm{Z}_{\mathrm{Ti}}(\mathrm{i}=\mathrm{A}, \mathrm{W}, \mathrm{S}, \mathrm{F})$-the fugacity capacity of each bulk compartment $\left(\mathrm{mol} \cdot \mathrm{m}^{-3} \cdot \mathrm{Pa}^{-1}\right)$;

$f_{i}(i=A, W, S, F)$-the fugacity $(P a)$;

$D_{i-j}(i, j=A, W, S, F)$-the rate of intermedia diffusion $\left(\mathrm{mol}^{-1} \cdot \mathrm{h}^{-1} \cdot \mathrm{Pa}^{-1}\right)$;

$D_{R i}(i=A, W, S, F)$-the rate of degradation in each bulk compartment $\left(m o l \cdot h^{-1} \cdot \mathrm{Pa}^{-1}\right)$;

$\mathrm{D}_{\mathrm{AR}}, \mathrm{D}_{\mathrm{PW}}, \mathrm{D}_{\mathrm{DW}}$-the rate of rain dissolution, wet deposition, dry deposition $\left(\mathrm{mol} \cdot \mathrm{h}^{-1} \cdot \mathrm{Pa}^{-1}\right)$;

$D_{D}, D_{R e}, D_{B S}$-the rate of sediment deposition, sediment resuspension, sediment burial $\left(\mathrm{mol}^{-1} \cdot \mathrm{h}^{-1} \cdot \mathrm{Pa}^{-1}\right)$;

$D_{\text {WO }}$-the rate of effluent in the water compartment $\left(\mathrm{mol}^{-1} \cdot \mathrm{h}^{-1} \cdot \mathrm{Pa}^{-1}\right)$;

$\mathrm{G}_{\mathrm{ow}}$-the flow into the reservoir $\left(\mathrm{m}^{3} / \mathrm{h}\right)$;

$\mathrm{Cow}^{-}$the concentration of the pollutant of the inflow $\left(\mathrm{mol} / \mathrm{m}^{3}\right)$

$E_{W}$-the rate of pollutants emission $(\mathrm{mol} / \mathrm{h})$.

\subsubsection{Model parameterisation}

The definitions and assignments of the original calculation parameters in the TBT and TPhT multimedia fugacity model are shown in Tables S1 and S2. The definitions and calculation equations of the intermediate parameters, which are fugacity capacity (Z-values) and the rates of transport and transformation (D-values), are shown in Tables 1 and 2 , respectively.

The octanol-water partition coefficient $\left(\mathrm{K}_{\mathrm{ow}}\right)$ and the organic carbon partition coefficient $\left(\mathrm{K}_{\mathrm{oc}}\right)$ were corrected using the formula $\mathrm{K}_{\mathrm{oc}}=0.4 \mathrm{~K}_{\mathrm{ow}}$ (Mackay, 2001). The degradation reaction rate constant and half-life were corrected with the formula $\tau_{1 / 2}=\ln 2 / k$ (Mackay, 2001). The correction formula for Henry's constant $(\mathrm{H})$ is shown in Table S3. Based on water level data, the corresponding areas and volumes of the TGR, functional relationships between the water level and area, and volumes of the TGR were obtained through binomial fitting. Some OT transport and transformation parameters vary with the environmental parameters of the TGR. For instance, the air-water mass transfer coefficient $\left(K_{V A}\right)$ is a 
function of wind speed, and the transfer coefficient of water-air $\left(\mathrm{K}_{\mathrm{vw}}\right)$ varies with the flow velocity and water depth. Both $\mathrm{K}_{\mathrm{VA}}$ and $\mathrm{K}_{\mathrm{VW}}$ were corrected using the formulas shown in Table S3.

In this study, emissions of TBT and TPhT were considered to include both leaching from ship hulls and runoff of TPhT pesticides. With reference to the literature (Yamamoto et al., 2009) and the Pollution Discharge Coefficient Method (Ma et al., 2012), the emissions of TBT and TPhT in the TGR were estimated as follows:

\section{See equations 5 and 6 in the supplemental files.}

where is the number of ships at ports; $k$ is the estimated proportion of ships that continue to use antifouling paints considering ship scrapping and new application, which was 1 prior to the implementation of the AFS Convention and 0.7 thereafter (Ding and Liu, 2018); is the proportion of each ship type: $28 \%, 47 \%, 2 \%, 20 \%$, and $3 \%$ for passenger ships, cargo ships, tugboats, non-transport ships, and fishing boats, respectively; is the proportion of boats with antifouling paint: 1 and 0.7 for the merchant ship and fishing boat classes, respectively (Champ, 2000); $\left(\mu \mathrm{g} \cdot \mathrm{cm}^{-2} \cdot \mathrm{d}^{-1}\right)$ is the leaching rate of OTs (TBT and TPhT): for TBT, this rate is 4.0 (berthing) and 5.1 (navigation) (Schatzberg, 1987), while for TPhT, it is 0.5 (berthing) and 1.0 (navigation); $(\mathrm{h})$ is berthing time, which is $1 \mathrm{~h}$ for a passenger ship or fishing boat and $25 \mathrm{~h}$ for all others; and are the representative length and width $(\mathrm{m})$, respectively, of the bottom of the ship, referring to the standard sizes of ships in the TGRR; is a correction factor for the ship bottom area: for cargo ships and fishing boats, this is 0.8 , while for other ships, it is $0.6 ; \mathrm{S}\left(\mathrm{km} \cdot \mathrm{h}^{-1}\right)$ is the speed of the ship, which is 27 when only commercial ships are considered; the value of is $1 \mathrm{~km} ;\left(\mathrm{kg} \cdot \mathrm{hm}^{-}\right.$ $2 \cdot a^{-1}$ ) is the pollutant discharge coefficient, with a value of $8.20 \times 10^{2}$ (Cheng, 2014); $\left(\mathrm{hm}^{2}\right)$ is the area of cultivated land; and is the coefficient of pollutant loss from cultivation, which is dimensionless with a value of 0.01 (Montforts, 2006).

\subsubsection{Model calculation and performance}

The simulation period was 24 months, from June 2010 to May 2012, corresponding to simulation times of months 1 to 24 , as shown in Figs. 3, 4, and $\mathbf{8}$. The year prior to the implementation of the AFS Convention was from June 2010 to May 2011, while the year after its implementation was from June 2011 to May 2012. Daily mean values were obtained through cubic-spline interpolation and used as the smallest unit of variation; a time step of 1 was used. The initial value of the simulation was the fugacity obtained using the model differential equations at $\mathrm{df} \mid \mathrm{t}=0$. Input parameters such as temperature, rainfall rate, inflow, and outflow were all defined as functions of time. The model was simulated using MATLAB R2016b, and the fourth-order Runge-Kutta method was used to numerically solve the differential equations to obtain $f$ for each compartment. After the model performance was evaluated, the concentration, transport flux, and mass flux were calculated for each compartment. Because the input parameters were dynamic, the results showed temporal variability. The process of modelling and computing is presented in Fig. $\mathbf{S 1 .}$ 
Water and sediment samples were collected in the reservoir region three times in 2012 (sampling sites are shown in Fig. 1) to obtain the concentrations of TBT and TPhT. Model performance was evaluated using Theil's inequality coefficient method (Min et al., 2010) and the percent bias method (Gupta et al., 1999) (SupplementaryText 1). In the water phase, the Theil's inequality coefficient values of TBT and TPhT were 0.1090 and 0.1388 , respectively, and the percent bias values were +0.1998 and +0.2237 , respectively. In the sediment phase, the Theil's inequality coefficient values of TBT and TPhT were 0.0631 and 0.1283 , respectively, and the percent bias values were -0.1345 and -0.2596 , respectively. Both of these compartments satisfied the criteria of Theil's inequality coefficient $<0.5$ and percent bias $\in[-0.7,+0.7]$ ( $\mathrm{Hu}$ et al., 2017), indicating that the prediction error of the model was acceptably small. Although the TBT and TPhT concentrations in fish in the TGR were not observed, the modelled concentrations of TPhT and TBT in the fish phase before implementation of the AFS Convention in this study were $73.51 \pm 13.10 \mathrm{ng} \mathrm{Sn} / \mathrm{g}$ and $0.31 \pm 0.05 \mathrm{ng} \mathrm{Sn} / \mathrm{g}$, respectively, which are similar to the findings by Hu et al. (2009) that the concentration of TPhT in the livers of Chinese sturgeon in the TGR was $68.0 \pm 31.2 \mathrm{ng} \mathrm{Sn} / \mathrm{g}$ and the concentration of TBT was $<1 \mathrm{ng} \mathrm{Sn/g}$. Therefore, the performance of the multimedia fugacity model developed in this study is considered adequate.

\subsubsection{Sensitivity and uncertainty in the model}

The sensitivity coefficient (SC) (Cao et al., 2004; Luo et al., 2008) was calculated to identify the influences of individual input parameters (Equation 7). The corresponding parameter can be regarded as a key input parameter when the SC is $>0.5$ (Lohman et al., 2000), showing that it has a strong impact on the model results. The results (Fig. S2) showed that $\mathrm{G}_{\mathrm{OW}}$ and $\mathrm{C}_{\mathrm{OW}}$ had strong impacts on predicted concentrations in all four compartments, with SC values near 1. The main source of OT pollution in the reservoir is the upper reaches of the river and its tributaries, with the TGR acting as an important sink of OTs. In addition,

$v_{p s}, U_{B S}, \omega_{o c w}, U_{D P}, \rho_{p w}, K_{o c}$ and $\rho_{p s}$ have major effects on the predicted concentrations of TBT and TPhT in the sediment compartment. $\mathrm{BCF}, \mathrm{K}_{\mathrm{FW}}$, and $\mathrm{K}_{\mathrm{WF}}$ strongly influence the predicted concentrations in the fish compartment. Accuracy in setting these parameters is essential for reliable simulation results.

\section{See equation 7 in the supplemental files.}

Here, $\mathrm{X}$ is the specified input parameter; $\mathrm{Y}$ is the corresponding result obtained from the model with input parameter variation; and $\mathrm{Y}(\mathrm{X} \mid \mathrm{F}=1)$ and $\mathrm{Y}(\mathrm{X} \mid \mathrm{F}=0.1)$ are the simulated concentrations when the specified parameter is multiplied by a factor of 1 and 0.1 , respectively.

Uncertainty arises from variability and numerical errors in various input parameters. Based on the results of sensitivity analysis, some of the input parameters selected were represented with probability density functions. Then, Monte Carlo simulation was performed 10,000 times for uncertainty analysis (Cao et al., 2004). The results are shown in Fig. S3. The coefficient of variation (CV) of the simulated concentration was $\leq 15 \%$, which was smaller than that of the measured concentration.

\subsection{Risk assessment}


The simulated concentrations of TBT and TPhT before and after implementation of the AFS Convention were applied to assess the ecological and health risk in the TGR.

\subsubsection{Ecological risk assessment}

The risk quotient (RQ) (Leung et al., 2006) was calculated to assess the ecological risk of TBT and TPhT for organisms in the TGR (Equation 8).

\section{See equation 8 in the supplemental files.}

Here, PEC represents the exposure concentration (ng Sn/L) in the water phase predicted by the model. PNEC represents the Predicted No-effect Concentration (ng Sn/L) which is from water quality criteria (WQC) and toxicity thresholds in published literature. If $R Q \geq 1$, the organisms in the aquatic environment are at significant risk. If $0.3 \leq R Q<1$, there is a potential risk. If $R Q<0.3$, there is no ecological risk (Leung et al., 2006).

\subsubsection{Health risk assessment}

The intake routes of TBT and TPhT including eating fish, drinking water, and skin absorption were considered in this study. The hazard index (HI, Equation 9) (USEPA, 1992) and tolerable average residue level (TARL, Equation 13) (Harino et al., 2003) of TBT and TPhT in fish were calculated to assess health risks in the TGRR.

\section{See equation 9 in the supplemental files.}

Here, $R f D_{j}$ is the reference dose $\left(\mu \mathrm{g} /\left(\mathrm{kg}_{\mathrm{bw}} \cdot \mathrm{d}\right)\right) \mathrm{a}$ : for TBT, the reference dose is 0.25 (Penninks, 1993), while for TPhT, it is 0.5(Tsuda et al., 1995); $A D D_{i}$ is the average daily dose (i represents one of the three routes: eating fish (F), drinking water (W) and skin absorption (S) $\left(\mu \mathrm{g} /\left(\mathrm{kg}_{\mathrm{bw}} \cdot \mathrm{d}\right)\right)$, which is estimated by Equation 10-12. If $H I>1$, there is a significant health risk to the population in the TGRR; if $H \mathrm{H}<1$, there is no health risk (USEPA, 2006).

\section{See equations $10-12$ in the supplemental files.}

Here, $c_{F}$ and $c_{W}$ are the simulated concentrations in fish $(\mathrm{ng} / \mathrm{g})$ and in water $(\mathrm{ng} / \mathrm{L})$, respectively; $I R_{F}$ is the average daily consumption of fish, which was calculated according to the annual consumption of fish and the population in the TGRR, and the value of that is $59.84 \mathrm{~g} / \mathrm{d} ; T F$ represents the OTs purification coefficient of the waterworks, which is 1 for both TBT and TPhT (Song et al., 2019; Streile et al., 1996); $I R_{W}$ denotes the average daily intake of drinking water, which is $2.3 \mathrm{~L} / \mathrm{d}$ for an adult(Duan et al., 2011); $k_{p}$ is the osmotic factor on the skin surface, which is $0.001 \mathrm{~cm} \cdot \mathrm{h}^{-1}$ (USEPA, 1992); $S A$ is the accessible skin surface area, which is $14150 \mathrm{~cm}^{2}$ for an adult (USEPA, 2011); $F$ denotes the skin exposure time, which is 1h(Zatoń and Szczepan, 2012); $A_{i}(i=F, W, S)$ means the absorption factor of eating fish, drinking water, and skin absorption, which are 100\%(Lee et al., 2016), 100\%(Duan et al., 2011), and 1\%(Yu et al., 2012), respectively; $B W$ denotes the body weight $(\mathrm{kg})$, which is $60 \mathrm{~kg}$ based on the average weight of Chinese. 


\section{See equation 13 in the supplemental files.}

Here, $T D /$ denotes tolerable daily intake $\left(\mu \mathrm{g} /\left(\mathrm{kg}_{\mathrm{bw}} \cdot \mathrm{d}\right)\right)$, for TBT, the TDI is 0.25 (Penninks, 1993), while for TPhT, it is $0.5(\mathrm{Lu}, 1995) . B W$ is the average body weight $(\mathrm{kg})$ of Chinese, which is $60 \mathrm{~kg}$. ADSC is average daily consumption of aquatic products, which is $59.84 \mathrm{~g} / \mathrm{d}$.

\section{Results And Discussion}

\subsection{Fate simulation of TBT and TPhT with water level fluctuations in the TGR}

\subsubsection{Concentration variations of TBT and TPhT in different phases}

Variations in the concentrations of TBT and TPhT during the simulation periods before and after the implementation of the AFS Convention are shown in Fig. 3. Compared with the concentrations before implementation of the AFS Convention, the average concentrations of TBT and TPhT in the water and fish phases decreased after implementation. The average concentration of TBT in the water phase decreased by $12.27 \%$ (from 4.36 to $3.83 \mathrm{ng} \mathrm{Sn/L}$ ), while that of TPhT decreased by $6.98 \%$ (from 2.19 to $2.04 \mathrm{ng} \mathrm{Sn/L).} \mathrm{The} \mathrm{average} \mathrm{concentration} \mathrm{of} \mathrm{TBT} \mathrm{and} \mathrm{TPhT} \mathrm{in} \mathrm{fish} \mathrm{showed} \mathrm{the} \mathrm{same} \mathrm{trend} \mathrm{as} \mathrm{in} \mathrm{water,}$ which means the decline of concentrations of TBT and TPhT in aquatic environment resulted in reducing the overall concentration level of TBT and TPhT in fish. These results showed that implementation of the AFS Convention reduced OT pollution, especially for TBT. Notably, for TBT, high concentrations in water phases occurred mainly during low-water periods. This pattern may be due to the inflow, outflow, and flow velocity increasing during low water periods, resulting in greater turbulence. The resuspension of sediment is a source of TBT that increases the concentrations in other phases.

Small peaks of TBT concentration also appeared in water phase during the winter high-water period, which may be due to the combined effects of more navigation, low degradation rate of TBT, and other factors. For TPhT, concentrations in the water and fish phases fluctuated slightly with water-level variations and seasonal changes, but were generally similar regardless of implementation of the AFS Convention. Aside from resuspension of sediment induced by turbulence during the flood season, fluctuations in concentrations of TPhT might be also related to the seasonal application of TPhT pesticides, soil erosion, and surface runoff (Gao et al., 2018; Gao et al., 2017).

Notably, the TBT and TPhT concentrations in the sediment phase fluctuated little during the simulation period, although the concentration of TPhT in the sediment phase showed a gradual increase throughout the simulation period. For TBT, the concentration in the sediment phase showed an increasing trend before the AFS Convention and continued to increase for 10 months after implementation of the AFS Convention. This delay may be due to the long half-lives of TBT and TPhT in sediment and their slow degradation rates. Choi et al. (2010) reported that TBT has a half-life of up to 17 years in sediment. The concentration of TBT was greater in the sediment phase than in the fish phase, while the concentration of TPhT was much greater in the fish phase than in the sediment phase. This difference indicates that TPhT 
accumulates more easily in fish because of bioaccumulation and biomagnification. The concentration simulated for the fish phase in this study represents the average level in a general distribution of fish species and is related to the overall resource availability and growth rate of fishes in the TGR. Seasonally mediated physiological changes, such as growth and metabolic compensation (Dong et al., 2004), as well as hydrologic alteration of the TGR (e.g., alternating water discharge and storage operations), can lead to variations in fish resources and their physiological activities, thereby affecting the pattern of OT accumulation in fish.

\subsubsection{Variations in transport and transfer fluxes $(N)$ among phases}

The percentage of $\mathrm{N}(\%)$ for all environmental processes are shown in Fig. 4(a). The $\mathrm{N}_{\mathrm{OW}}, \mathrm{N}_{\mathrm{WO}}$, and $\mathrm{N}_{\mathrm{RW}}$ values were highest for TBT during the simulation period, with average proportions of $43.32 \%, 20.04 \%$, and $21.13 \%$, respectively, indicating that advection and degradation in water were important multimedia transfer and transport processes affecting TBT. The percentage of $\mathrm{N}$ between water and sediment was also high, comprising $9.92 \%$ of the total. TBT accumulated in sediment mainly through the deposition of particles, while resuspension was the main process by which TBT was released from the sediment into the water. These two processes were both significantly affected by the operation of the TGR. Despite the fact that advection, degradation in water, and transport between water and sediment were important for both TBT and TPhT, for TPhT $\mathrm{N}_{\mathrm{FW}}$ and $\mathrm{N}_{\mathrm{WF}}$ were more dominant than that for TBT. This may be because TPhT has greater biosorption capacity and lipid solubility than TBT (Avery et al., 1993; Avery et al., 1991), and fish have a certain ability to metabolize TBT in contrast to TPhT (Borghi and Porte, 2002), which allow it a preferential accumulate of TPhT in fish to exhibit more significant bioaccumulation and biomagnification effects (Stab et al., 1996; Yamada et al., 1997).

The $N$ values of TBT and TPhT varied regularly with fluctuations of the water level in the TGR (Fig. 4(b)). The peak $\mathrm{N}$ values for TBT occurred during the discharge period at low water; there are two possible reasons for this phenomenon. First, the low-water period was during summer in the TGR, when high temperatures led to an increase in the degradation rate constant of TBT in the water column. In addition, flooding resulted in greater inflow and outflow, leading to enhanced turbulence. For TPhT, $\mathrm{N}_{\mathrm{FW}}$ and $\mathrm{N}_{\mathrm{WF}}$ increased during the discharge period, then decreased when the storage period began. This pattern may have manifested because fish resources and their physiological activities were most abundant during the discharge period of the TGR, resulting in increased transport between the fish and water.

\subsubsection{Mass fluxes and residue levels of TBT and TPhT before and after implementation of the AFS Convention}

The cumulative mass fluxes and residue levels for the year before and the year after implementation of the AFS Convention are shown in Fig. 5. For the year after the AFS Convention was implemented, most of the cumulative mass fluxes of TBT and TPhT decreased. In contrast, cumulative mass fluxes from the sediment to water and for sediment burial both increased slightly. The calculated residue levels for the four phases before and after the AFS Convention exhibited the same sequence: sediment $>$ water $>$ fish > 
atmosphere. Residues of TBT and TPhT in the sediment after implementation of the AFS Convention increased by $24.67 \%$ and $92.91 \%$, respectively. This result may be related to the properties of TBT and TPhT, which are readily adsorbed onto particles and have long half-lives. This result also revealed that the sediment is an important sink of both TBT and TPhT. This sink can be transformed into a source that is non-negligible under certain conditions. After the TGR began operation, more sediment was produced due to the water storage, thereby emphasising the sink and source properties of the sediment and increasing the levels of OTs in the aquatic environment.

After the AFS Convention was implemented, the residue levels of the atmosphere, water, and fish were reduced by $21.21 \%, 11.24 \%$, and $12.23 \%$ for TBT and $18.68 \%, 5.87 \%$, and $6.91 \%$ for TPhT, respectively; however, the total contents of TBT and TPhT in the system increased by $15.20 \%$ and $38.10 \%$, respectively. This result suggests that although implementation of the AFS Convention had the effect of reducing OT pollution, the residue levels of TBT and TPhT in the overall TGR system remained high and continued to increase. In particular, the sediment properties of both sink and source areas affect the concentrations of OTs in aquatic systems for an extended duration. The calculation results also showed that $1460.51 \mathrm{~kg}$ TBT and $716.48 \mathrm{~kg}$ TPhT entered the lower reaches of the TGR within one year after implementation of the AFS Convention, which may pose risks to downstream aquatic organisms and populations.

\subsection{Ecological risk assessment of TBT and TPhT for organisms in the TGR}

Considering the high toxicity and bioaccumulation characteristics of TBT and TPhT, many countries and researchers have established standards and risk thresholds for OTs. Previous studies showed that the acute thresholds for both TBT and TPhT were greater than $48 \mathrm{ng} \mathrm{Sn/L} \mathrm{(Fargasova,} \mathrm{1997;} \mathrm{RIVM,} \mathrm{2012a;}$ Roessink et al., 2006; USEPA, 2003; Wen et al., 2018; Yi et al., 2012), while the maximum concentrations predicted for TBT and TPhT during the simulation period in this study were 6.67 and $2.73 \mathrm{ng} \mathrm{Sn} / \mathrm{L}$, respectively; therefore, the acute risk for organisms in the TGR is negligible.

In contrast, the chronic ecological risks of TBT and TPhT to aquatic organisms in the TGR were more severe. RQ values calculated using different criteria and chronic exposure thresholds are shown in Fig. 6. These results show that the decline in chronic ecological risk from TBT and TPhT after implementation of the AFS Convention has not been robust. For TBT, all RQ values were greater than 1 , with a maximum of 59.84 (RIVM, 2012a); therefore, TBT posed a significant chronic ecological risk to aquatic organisms in the TGR, and may cause chronic toxicity in aquatic organisms (ANZECC, 2000; Babut et al., 2003; Hall et al., 2000; RIVM, 2012a; USEPA, 2003), such as oyster calcification abnormalities (Alzieu, 1998) and weight loss and imposex in snails (Gibbs, 1987). For TPhT, most RQ values were greater than 1 , with a maximum of 16.83 (RIVM, 2012b). In particular, RQ values calculated using the endpoints of suppressed spawning frequency (Zhang et al., 2008), eye defects in embryos or larvae (Zhang et al., 2008), and imposex in snails (Yi et al., 2012) were all greater than 1, suggesting that the chronic ecological risk of TPhT in the TGR cannot be ignored. 


\subsection{Health risks from TBT and TPhT to the population of the TGRR}

Calculation of the average daily dose (ADD) in the TGRR showed that for TBT, ADD $s(47.01 \%)>A_{f} D_{f}$ $(34.65 \%)>A D_{w}(18.34 \%)$, indicating that the intake of TBT occurs mainly through skin absorption when swimming or bathing. For TPhT, $\operatorname{ADD}_{f}(99.59 \%)>A_{D D}(0.29 \%)>A_{W}(0.11 \%)$, indicating that the intake of TPhT occurs mainly through eating fish. The results of the health risk assessment are shown in Fig. 7. The hazard index values of TBT ranged from 0.0032 to 0.0161 , and those of TPhT ranged from 0.34 to 0.60. The hazard index values of both TBT and TPhT were less than 1, suggesting that health risks to the population in the TGRR from TBT and TPhT were low during the simulation period (USEPA, 2007). Compared with TBT, TPhT carried a higher health risk for the population, as its highest hazard index value $(0.60)$ during the simulation period was near 1.

The calculation of tolerable average residue level (TARLs) showed that the TARL of TBT was $92.09 \mathrm{ng}$ $\mathrm{Sn} / \mathrm{g}$, while that of TPhT was $154.38 \mathrm{ng} \mathrm{Sn} / \mathrm{g}$. The maximum simulated concentration $(0.48 \mathrm{ng} \mathrm{Sn} / \mathrm{g})$ of TBT in fish during the simulation period was much lower than the TARL of TBT, while the maximum TPhT level (91.59 $\mathrm{ng} \mathrm{Sn} / \mathrm{g}$ ) was close to the TARL of TPhT. These results indicate that TPhT contamination of aquatic products is a serious problem in the TGRR. The TARLs of TBT and TPhT in Taiwan were calculated by Lee et al. (2016); these were $88.6 \mathrm{ng} \mathrm{Sn} / \mathrm{g}$ and $149.4 \mathrm{ng} \mathrm{Sn} / \mathrm{g}$, respectively. The TARL of total butyltin ( $\sum$ BTs $=$ TBT + dibutyltin + monobutyltin) in seafood from Chinese Bohai coastal waters, calculated by Yang et al. (2006), was $90.8 \mathrm{ng} \mathrm{Sn/g}$. The previous results are similar to those of the present study.

Although the health risk of TBT in the TGRR was low, a previous study found that, in some locations, the concentration of TBT reached $161.82 \mathrm{ng} \mathrm{Sn/L}$ in 2010 and $393.35 \mathrm{ng} \mathrm{Sn/L}$ in 2012 (Gao et al., 2013); thus, TBT posed much greater health risks to the populations of some areas within the TGRR. Moreover, for TPhT, the average daily intake of aquatic products (ADSC) in the TGRR was $59.84 \mathrm{~g} /$ day. Fisheries in the TGRR have expanded, and the ADSC of some populations may be much greater than the reported value; fishermen or those who have a preference for fish will experience greater health risks. In addition, the simulated concentration of TPhT represents the average level in the TGRR. For some specific fish or regions, the concentration of TPhT in the fish phase may be greater and therefore pose an increased health risk to the population.

With the rapid development of agriculture and aquaculture in China, the application of TPhT as a fungicide and insecticide may increase over the next few years or decades (Chen et al., 2019); notably, TPhT is not yet regulated by the Chinese government. Thus, comprehensive monitoring and strategic management of TPhT pollution are essential to controlling the contamination level in the TGRR, especially in sensitive areas such as source regions of potable water, in order to reduce the health risks from TPhT to the population of the TGRR. 


\section{Conclusions}

A multimedia fugacity model was developed to simulate the fate, transfer, and transport of TBT and TPhT before and after implementation of the AFS Convention while considering water level fluctuations in the TGR. The simulation results were used to assess ecological and health risks in the TGRR. The simulation results revealed that implementation of the AFS Convention reduced both TBT and TPhT concentrations in three of the four phases considered in this study, but not in sediment. The reduction of TBT was more robust than that of TPhT. However, TBT and TPhT in sediment and the overall system remained at high levels and continued to increase. The concentrations of TBT and TPhT, as well as the transfer and transport fluxes in each phase, varied periodically with the cycle of reservoir regulation and water level. Sediment is an important source and sink of TBT and TPhT, and the alternation of these two roles became more apparent with water level fluctuations, affecting the concentrations of OTs in the aquatic environment over an extended period. TBT and TPhT pose significant chronic risks to aquatic organisms in the reservoir area, and the risk from TBT is greater than that from TPhT. Based on average levels, TBT and TPhT pollution in the TGRR do not pose significant health risks to the population. However, the health risk from TPhT, mainly due to intake of contaminated fish, is of concern, especially to populations that engage in greater intake of aquatic products in some areas of the TGRR. Therefore, continuous monitoring and effective management measures are essential for controlling OT pollution in the TGRR.

\section{Declarations}

Ethics approval and consent to participate: Not applicable.

Consent for publication: Not applicable.

Availability of data and materials: The datasets supporting the conclusions of this article are included within the article and its supplementary material.

Competing interests: The authors declare that they have no competing interests.

Funding: This study was financially supported by National Natural Science Foundation of China [21976021], National Key Research and Development Program of China (2019YFD1100504, 2019YFD1100501), and Natural Science Foundation Project of CQ CSTC (cstc2017jcyjAX0025).

Authors' contributions: JG developed the model, and performed data analysis and manuscript writing. PF made contributions to model developing, testing and running. $\mathrm{XC}$ collected the original datasets of the model. JG and XH gave good suggestions on the interpretation of simulation data. JZ and ZC paid much attention on manuscript revision. All authors read and approved the final manuscript.

Acknowledgements: Not applicable. 


\section{Abbreviations}

TGR: Three Gorges Reservoir; TGRR: Three Gorges Reservoir Region;

TBT: tributyltin; TPhT: triphenyltin; OT: organotin;

AFS Convention: The International Convention on the Control of Harmful Anti-fouling Systems on Ships.

\section{References}

1. Alzieu, C., 1998. Tributyltin: case study of a chronic contaminant in the coastal environment. Ocean Coast. Manage. 40: 23-36. http://dx.doi.org/10.1016/S0964-5691(98)00036-2

2. Anastasiou, Thekla I., Chatzinikolaou Eva, Mandalakis Manolis, Arvanitidis Christos, 2016. Imposex and organotin compounds in ports of the Mediterranean and the Atlantic: Is the story over? Sci. Total Environ. 569-570: 1315-1329. http://dx.doi.org/10.1016/j.scitotenv.2016.06.209

3. ANZECC (Australian and New Zealand Environment and Conservation Council Canberra),2000. Australian and New Zealand Guidelines for Fresh and Marine Water Quality.https://www.waterquality.gov.au/anz-guidelines/guideline-values/default (accessed 16 August 2019)

4. Arzaghi, Ehsan, Abbassi Rouzbeh, Garaniya Vikram, Binns Jonathan, Khan Faisal, 2018. An ecological risk assessment model for Arctic oil spills from a subsea pipeline. Mar. Pollut. Bull. 135: 1117-1127. http://dx.doi.org/10.1016/j.marpolbul.2018.08.030

5. Avery, Simon V., Miller Marvin E., Gadd Geoffrey M., Codd Geoffrey A., Cooney Joseph J., 1991. Toxicity of organotins towards cyanobacterial photosynthesis and nitrogen fixation. Fems Microbiol. Lett. 84: 205-210. http://dx.doi.org/10.1111/j.1574-6968.1991.tb04597.x

6. Babut, Marc, Corinne Bonnet, Marc Bray, Patrick Flammarion, Jeanne Garric, Geneviève Golaszewski, 2003. Developing environmental quality standards for various pesticides and priority pollutants for French freshwaters. J. Environ. Manage. 69: 139-147. http://dx.doi.org/10.1016/S03014797(03)00133-6

7. Batista-Andrade, Jahir Antonio, Caldas Sergiane Souza, Batista Rodrigo Moço, Castro Italo Braga, Fillmann Gilberto, Primel Ednei Gilberto, 2018. From TBT to booster biocides: Levels and impacts of antifouling along coastal areas of Panama. Environ. Pollut. 234: 243-252. http://dx.doi.org/10.1016/j.envpol.2017.11.063

8. Borghi, V., Porte C., 2002. Organotin pollution in deep-sea fish from the northwestern Mediterranean. Environ. Sci. Technol. 36: 4224-4228. http://dx.doi.org/10.1021/es025725c

9. Cao, H. Y., Tao S., Xu F. L., Coveney R. M., Cao J., Li B. G., et al., 2004. Multimedia fate model for hexachlorocyclohexane in Tianjin, China. Environ. Sci. Technol. 38: 2126-2132. http://dx.doi.org/10.1021/es0305860

10. CCME (Canadian Council of Resource and Environment Ministers), 1992. Appendix X-Canadian Water Quality Guidelines: Updates (March 1992), Organotins and Halogenated Methanes. Canadian 
Water Quality Guidelines.

11. Champ, M. A., 2000. A review of organotin regulatory strategies, pending actions, related costs and benefits. Sci. Total Environ. 258: 21-71. http://dx.doi.org/10.1016/S0048-9697(00)00506-4

12. Chen, Chunzhao, Chen Ling, Huang Qinghui, Chen Zhaoying, Zhang Wen, 2019. Organotin contamination in commercial and wild oysters from China: Increasing occurrence of triphenyltin. Sci. Total Environ. 650: 2527-2534. http://dx.doi.org/10.1016/j.scitotenv.2018.09.310

13. Cheng, E. Y, 2014. Prospects of golden apple snail control in Taiwan. APEC Symposium on the Management of the Golden Apple Snail. Taipei: Council of Agriculture, 5 pp, Pingtung, Taiwan.

14. Choi, Minkyu, Moon Hyo-Bang, Yu Jun, Eom Ji-Yeong, Choi Hee-Gu, 2010. Temporal Trend of Butyltins in Seawater, Sediments, and Mussels from Busan Harbor of Korea Between 2002 and 2007 : Tracking the Effectiveness of Tributylin Regulation. Arch. Environ. Con. Tox. 58: 394-402. http://dx.doi.org/10.1007/s00244-009-9428-2

15. Dale, Amy L., Casman Elizabeth A., Lowry Gregory V., Lead Jamie R., Viparelli Enrica, Baalousha Mohammed, 2015. Modeling Nanomaterial Environmental Fate in Aquatic Systems. Environ. Sci. Technol. 49: 2587-2593. http://dx.doi.org/10.1021/es505076w

16. DERFA, 2017. Guidance: Hazardous Substances to Groundwater: Minimum Reporting Values. The UK Environment Agency.

17. Di Guardo, Antonio, Gouin Todd, MacLeod Matthew, Scheringer Martin, Institutionen För Miljövetenskap Och Analytisk, Stockholms Universitet, et al., 2018. Environmental fate and exposure models: advances and challenges in 21 st century chemical risk assessment. Environ. Sci.-Process Impacts. 2: 58-71. http://dx.doi.org/10.1039/c7em00568g

18. Ding, Huangyan, Liu Wanqi, 2018. The case set of the logistics industry in the Three Gorges Reservoir region. BEIJING BOOK CO. INC.

19. Dong, C. D., Chen C. W., Liu L. L., 2004. Seasonal variation in the composition and concentration of butyltin compounds in marine fish of Taiwan. Environ. Pollut. 131: 509-514. http://dx.doi.org/10.1016/j.envpol.2004.01.011

20. Duan, Xiao-li, Wang Zong-shuang, Li Qin, Zhang Wen-jie, Huang Nan, Wang Bei-bei, et al., 2011. Health risk assessment of heavy metals in drinking water based on field measurement of exposure factors of Chinese people. Environmental Science. 32: 1329-1339.

21. Duran, I., Beiras R., 2017. Acute water quality criteria for polycyclic aromatic hydrocarbons, pesticides, plastic additives, and 4-Nonylphenol in seawater. Environ. Pollut. 224: 384-391. http://dx.doi.org/10.1016/j.envpol.2017.02.018

22. EU (European Union), 2008. Directive 2008/105/EC of the European Parliament and of the Council of 16 December 2008 on environmental quality standards in the field of water policy, amending and subsequently repealing Council Directives 82/176/EEC, 83/513/EEC, 84/156/EEC, 84/491/EEC, 86/280/EEC and amending Directive 2000/60/EC of the European Parliament and of the Council. http://data.europa.eu/eli/dir/2008/105/2013-09-13 (accessed 16 August 2019 ). 
23. Fargasova, A., 1997. Comparative study of ecotoxicological effect of triorganotin compounds on various biological subjects. Ecotox. Environ. Safe. 36: 38-42.

http://dx.doi.org/10.1006/eesa.1996.1483

24. Finnegan, Christopher, Ryan David, Enright Anne-Marie, Garcia-Cabellos Guiomar, 2018. A review of strategies for the detection and remediation of organotin pollution. Crit. Rev. Env. Sci. Tec. 48: 77118. http://dx.doi.org/10.1080/10643389.2018.1443669

25. Gao, Jun-min, Chen Xiao-ling, Sun Xiu-qian, Zhang Ke, Chen You-peng, Guo Jin-song, et al., 2018. Occurrence of organotins in the aquatic environment during an operating cycle of the Three Gorges Reservoir, China. Environ. Sci. Pollut. R. 25: 1731-1741. http://dx.doi.org/10.1007/s11356-017-0585-y

26. Gao, Jun-Min, Wu Lei, Chen You-Peng, Zhou Bin, Guo Jin-Song, Zhang Ke, et al., 2017. Spatiotemporal distribution and risk assessment of organotins in the surface water of the Three Gorges Reservoir Region, China. Chemosphere. 171: 405-414. http://dx.doi.org/10.1016/j.chemosphere.2016.12.089

27. Gao, Jun-Min, Zhang Ying, Guo Jin-Song, Jin Fen, Zhang Ke, 2013. Occurrence of organotins in the Yangtze River and the Jialing River in the urban section of Chongqing, China. Environ. Monit. Assess. 185: 3831-3837. http://dx.doi.org/10.1007/s10661-012-2832-5

28. Gibbs, Pe, 1987. The use of the dog-whelk, Nucella lapillus, as an indicator of tributyltin (TBT) contamination. J. Mar. Biol. Assoc. UK. 67: 507.

29. Gupta, Hoshin Vijai, Sorooshian Soroosh, Yapo Patrice Ogou, 1999. Status of Automatic Calibration for Hydrologic Models: Comparison with Multilevel Expert Calibration. J. Hydrol. Eng. 4: 135-143. http://dx.doi.org/10.1061/(ASCE)1084-0699(1999)4:2(135)

30. Hall, Lenwood W., Scott Mark C., Killen William D., Unger Michael A., 2000. A Probabilistic Ecological Risk Assessment of Tributyltin in Surface Waters of the Chesapeake Bay Watershed. Hum. Ecol. Risk Assess. 6: 141-179. http://dx.doi.org/10.1080/10807030091124482

31. Harino, H., O'Hara SCM, Burt G. R., Chesman B. S., Pope N. D., Langston W. J., 2003. Organotin compounds in Mersey and Thames Estuaries a decade after UK TBT legislation. J. Mar. Biol. Assoc. UK 83: 11-22. http://dx.doi.org/https://doi.org/10.1017/S0025315403006738h

32. Hu, Jianying, Zhang Zhaobin, Wei Qiwei, Zhen Huajun, Zhao Yanbin, Peng Hui, et al., 2009. Malformations of the endangered Chinese sturgeon, Acipenser sinensis, and its causal agent. P. Natl Acad. Sci. USA. 106: 9339-9344. http://dx.doi.org/10.1073/pnas.0809434106

33. Hu, Mingfeng, Liu Xingang, Wu Xiaohu, Dong Fengshou, Xu Jun, Chen Wuying, et al., 2017. Characterization of the fate and distribution of ethiprole in water-fish-sediment microcosm using a fugacity model. Sci. Total Environ. 576: 696-704. http://dx.doi.org/10.1016/j.scitotenv.2016.10.087

34. Kotake, Yaichiro, 2012. Molecular Mechanisms of Environmental Organotin Toxicity in Mammals. Biol. Pharm. Bull. 35: 1876-1880. http://dx.doi.org/10.1248/bpb.b212017

35. Lee, Ching-Chang, Hsu Ya-Chen, Kao Yi-Ting, Chen Hsiu-Ling, 2016. Health risk assessment of the intake of butyltin and phenyltin compounds from fish and seafood in Taiwanese population. Chemosphere. 164: 568-575. http://dx.doi.org/10.1016/j.chemosphere.2016.08.141 
36. Leung, Kenneth M. Y., Kwong Rita P. Y., Ng W. C., Horiguchi Toshihiro, Qiu J. W., Yang Ruiqiang, et al., 2006. Ecological risk assessments of endocrine disrupting organotin compounds using marine neogastropods in Hong Kong. Chemosphere. 65: 922-938.

http://dx.doi.org/10.1016/j.chemosphere.2006.03.048

37. Lohman, K., Pai P., Seigneur C., Levin L., 2000. Sensitivity analysis of mercury human exposure. Sci. Total Environ. 259: 3-11. http://dx.doi.org/10.1016/S0048-9697(00)00530-1

38. Lu, F. C., 1995. A Review of the Acceptable Daily Intakes of Pesticides Assessed by WHO. Regul. Toxicol. Pharm. 21: 352-364. http://dx.doi.org/https://doi.org/10.1006/rtph.1995.1049

39. Luo, Yuzhou, Zhang Xuyang, Liu Xingmei, Ficklin Darren, Zhanga Minghua, 2008. Dynamic modeling of organophosphate pesticide load in surface water in the northern San Joaquin Valley watershed of California. Environ. Pollut. 156: 1171-1181. http://dx.doi.org/10.1016/j.envpol.2008.04.005

40. Ma, Guoxia, Yu Fun, Cao Dong, Niu Kunyu, 2012. Calculation of agricultural non-point source pollution emission in China and its long-term forecast. Acta Scientiae Circumstantiae. 32: 489-497.

41. Mackay, D., Hickie B., 2000. Mass balance model of source apportionment, transport and fate of PAHs in Lac Saint Louis, Quebec. Chemosphere. 41: 681-692. http://dx.doi.org/10.1016/S00456535(99)00486-5

42. Mackay, Donald, 2001. Multimedia Environmental Models-The Fugacity Approach, Lewis Publishers, U.S.

43. Meng, Pei-Jie, Lin Junda, Liu Li-Lian, 2009. Aquatic organotin pollution in Taiwan. J. Environ. Manage. 901: S8-S15. http://dx.doi.org/10.1016/j.jenvman.2008.06.008

44. Min, Fei-Yan, Yang Ming, Wang Zi-Cai, 2010. Knowledge-based method for the validation of complex simulation models. Simul. Model. Pract. Th. 18: 500-515.

http://dx.doi.org/10.1016/j.simpat.2009.12.006

45. Montforts, Mark H. M. M., 2006. Assessment of persistency and bioaccumulation in pesticide registration frameworks within the organization for economic cooperation and development. Integr. Environ. Assess. Manag. 2: e1-e6. http://dx.doi.org/10.1002/ieam.5630020117

46. Negri, Andrew, Marshall Paul, 2009. TBT contamination of remote marine environments: Ship groundings and ice-breakers as sources of organotins in the Great Barrier Reef and Antarctica. J. Environ. Manage. 901: S31-S40. http://dx.doi.org/10.1016/j.jenvman.2008.06.009

47. Ranke, Johannes, 2002. Persistence of Antifouling Agents in the Marine Biosphere. Environ. Sci. Technol. 36: 1539-1545. http://dx.doi.org/10.1021/es011155p

48. RIVM (National Institute for Public Health and the Environment), Ministry of health, Welfare and Sport, 2012a. Environmental risk limits for organotin compounds, RIVM report 607711009/2012.

49. RIVM (National Institute for Public Health and the Environment), Ministry of health, Welfare and Sport, 2012b. Environmental risk limits for triphenyltin in water, RIVM Report 601714018/2012.

50. Roessink, I., Belgers J. D. M., Crum S. J. H., van den Brink P. J., Brock T. C. M., 2006. Impact of triphenyltin acetate in microcosms simulating floodplain lakes. II. Comparison of species sensitivity 
distributions between laboratory and semi-field. Ecotoxicology. 15: 411-424.

http://dx.doi.org/10.1007/s10646-006-0063-7

51. Santos, Miguel Machado, Reis-Henriques Maria Armanda, Vieira Maria Natividade, Sole Montserrat, 2006. Triphenyltin and tributyltin, single and in combination, promote imposex in the gastropod Bolinus brandaris. Ecotox. Environ. Safe. 64: 155-162.

http://dx.doi.org/10.1016/j.econenv.2005.02.003

52. Schatzberg, P, 1987. Organotin Antifouling Hull Paints and the U.S. Navy-A Historical Perspective. Oceans, 1987.

53. Sonak, Sangeeta, Pangam Prajwala, Giriyan Asha, Hawaldar Kavita, 2009. Implications of the ban on organotins for protection of global coastal and marine ecology. J. Environ. Manage. 901: S96-S108. http://dx.doi.org/10.1016/j.jenvman.2008.08.017

54. Song, Zi, Zhang Xinbo, Ngo Huu Hao, Guo Wenshan, Wen Haitao, Li Chaocan, 2019. Occurrence, fate and health risk assessment of 10 common antibiotics in two drinking water plants with different treatment processes. Sci. Total Environ. 674: 316-326.

http://dx.doi.org/10.1016/j.scitotenv.2019.04.093

55. Stab, J. A., Traas T. P., Stroomberg G., VanKesteren J., Leonards P., VanHattum B., et al., 1996. Determination of organotin compounds in the foodweb of a shallow freshwater lake in the Netherlands. Arch. Environ. Con. Tox. 31: 319-328. http://dx.doi.org/10.1007/s002449900115

56. Streile, G. P., Shields K. D., Stroh J. L., Bagaasen L. M., Whelan G., Mcdonald J. P., et al., 1996. The Multimedia Environmental Pollutant Assessment System (MEPAS)\{reg_sign\}: Source-term release formulations. Environmentalences.

57. Su, Chao, Zhang Hong, Cridge Claudia, Liang Ruoyu, 2019. A review of multimedia transport and fate models for chemicals: Principles, features and applicability. Sci. Total Environ. 668: 881-892. http://dx.doi.org/10.1016/j.scitotenv.2019.02.456

58. Sun, Chang, Dong Deming, He Sinan, Zhang Liwen, Zhang Xun, Wang Chaoqian, et al., 2019. Multimedia fate modeling of antibiotic sulfamethoxazole, lincomycin, and florfenicol in a seasonally ice-covered river receiving WWTP effluents. Environ. Sci. Pollut. R. 26: 17351-17361. http://dx.doi.org/10.1007/s11356-019-05121-1

59. Sun, Lingbin, Zhang Jiliang, Zuo Zhenghong, Chen Yixin, Wang Xinhong, Huang Xin, et al., 2011. Influence of triphenyltin exposure on the hypothalamus-pituitary-gonad axis in male Sebastiscus marmoratus. Aquat. Toxicol. 104: 263-269. http://dx.doi.org/10.1016/j.aquatox.2011.04.018

60. Tsuda, T., Inoue T., Kojima M., Aoki S., 1995. Daily intakes of tributyltin and triphenyltin compounds from meals. J. Aoac Int. 78: 941-943.

61. USEPA (United States Environmental Protection Agency), 2003. Ambient Aquatic Life Water Quality Criteria for Tributyltin (TBT) - Final /Office of Water 4304T/EPA 822-R-03-031.

62. USEPA (United States Environmental Protection Agency), 2006. National primary drinking water regulations: stage 2 disinfectants and disinfection by products rule: final rule. Fed. Regist 71. 
63. USEPA (United States Environmental Protection Agency), 2011. Exposure factors handbook. In: Washington DC Office Of Research And Development.

64. USEPA, 2007. Appendix E: Risk quotient method and LOCs-risks of metolachlor use to federally listed endangered barton springs salamander[S].

65. USEPA(United States Environmental Protection Agency), 1992. Guidelines for exposure assessment FRL4129-5. Washington DC: Office of Health and Environmental Assessment. Federal Register 57(104):22888-22938.

66. Wang, Ce, Feng Yujie, Sun Qingfang, Zhao Shanshan, Gao Peng, Li Bai-Lian, 2012. A multimedia fate model to evaluate the fate of PAHs in Songhua River, China. Environ. Pollut. 164: 81-88. http://dx.doi.org/10.1016/j.envpol.2012.01.025

67. Wen, Jingjing, Cui Xiaoying, Gibson Mark, Li Zhengyan, 2018. Water quality criteria derivation and ecological risk assessment for triphenyltin in China. Ecotox. Environ. Safe. 161: 397-401. http://dx.doi.org/10.1016/j.ecoenv.2018.06.012

68. Xu, Yaoyang, Cai Qinghua, Shao Meiling, Han Xinqin, Cao Ming, 2009. Seasonal dynamics of suspended solids in a giant subtropical reservoir (China) in relation to internal processes and hydrological features. Quaternary International 208: 138-144.

http://dx.doi.org/10.1016/j.quaint.2008.12.019

69. Yamada, H., Takayanagi K., Tateishi M., Tagata H., Ikeda K., 1997. Organotin compounds and polychlorinated biphenyls of livers in squid collected from coastal waters and open oceans. Environ. Pollut. 96: 217-226. http://dx.doi.org/10.1016/S0269-7491(97)00019-5

70. Yamada, Shigeru, Asanagi Miki, Hirata Naoya, Itagaki Hiroshi, Sekino Yuko, Kanda Yasunari, 2016. Tributyltin induces mitochondrial fission through Mfn1 degradation in human induced pluripotent stem cells. Toxicol. In Vitro. 34: 257-263. http://dx.doi.org/10.1016/j.tiv.2016.04.013

71. Yamamoto, Joji, Yonezawa Yoshitaka, Nakata Kisaburo, Horiguchi Fumio, 2009. Ecological risk assessment of TBT in Ise Bay. J. Environ. Manage. 90: S41-S50. http://dx.doi.org/10.1016/j.jenvman.2008.08.016

72. Yang, R. Q., Zhou Q. F., Liu J. Y., Jiang G. B., 2006. Butyltins compounds in molluscs from Chinese Bohai coastal waters. Food Chem. 97: 637-643. http://dx.doi.org/10.1016/j.foodchem.2005.03.049

73. Ye, Jinshao, Yin Hua, Peng Hui, Bai Jieqiong, Xie Danping, Wang Linlin, 2013. Biosorption and biodegradation of triphenyltin by Brevibacillus brevis. Bioresource Technol. 129: 236-241. http://dx.doi.org/10.1016/j.biortech.2012.11.076

74. Yi, Andy Xianliang, Leung Kenneth M. Y., Lam Michael H. W., Lee Jae Seong, Giesy John P., 2012. Review of measured concentrations of triphenyltin compounds in marine ecosystems and metaanalysis of their risks to humans and the environment. Chemosphere. 89: 1015-1025. https://doi.org/10.1016/j.chemosphere.2012.05.080

75. Yu, Yingxin, Li Chunlei, Zhang Xiaolan, Zhang Xinyu, Pang Yuping, Zhang Shaohuan, et al., 2012. Route-specific daily uptake of organochlorine pesticides in food, dust, and air by Shanghai residents, China. Environ. Int. 50: 31-37. http://dx.doi.org/10.1016/j.envint.2012.09.007 
76. Zatoń, Krystyna, Szczepan Stefan, 2012. The Effect of Immediate Verbal Feedback on the Efficiency and the Effectiveness of Swimming. Baltic Journal of Health and Physical Activity. 4(2).

77. Zhang, Zhaobin, Hu Jianying, Zhen Huajun, Wu Xiaoqin, Huang Chong, 2008. Reproductive Inhibition and Transgenerational Toxicity of Triphenyltin on Medaka (Oryzias latipes) at Environmentally Relevant Levels. Environ. Sci. Technol. 42: 8133-8139. http://dx.doi.org/10.1021/es801573x

\section{Tables}

Table 1 Calculation equations of Z-values $\left(\mathrm{mol} \cdot \mathrm{m}^{-3} \cdot \mathrm{Pa}^{-1}\right)$

\begin{tabular}{cccc}
\hline Bulk compartment & Sub-compartment & Calculation equation & Z-value \\
\hline Atmosphere & Air & $\mathrm{Z}_{\mathrm{A}}=1 / \mathrm{RT}$ & $\mathrm{Z}_{\mathrm{TA}}=\mathrm{Z}_{\mathrm{A}}+\mathrm{Z}_{\mathrm{PA}} \mathrm{v}_{\mathrm{pa}}$ \\
& Aerosols & $\mathrm{Z}_{\mathrm{PA}}=6 \times 10^{6} \mathrm{Z}_{\mathrm{A}} / \mathrm{p}$ & \\
\hline Water & Water & $\mathrm{Z}_{\mathrm{W}}=1 / \mathrm{H}$ & $\mathrm{Z}_{\mathrm{TW}}=\mathrm{Z}_{\mathrm{W}}+\mathrm{Z}_{\mathrm{PW}} \mathrm{v}_{\mathrm{pw}}$ \\
& Suspended solids & $\mathrm{Z}_{\mathrm{PW}}=\mathrm{Z}_{\mathrm{W}} \rho_{\mathrm{pw}} \mathrm{K}_{\mathrm{oc}} \omega_{\mathrm{ocw}}$ & \\
\hline Sediment & Pore water & $\mathrm{Z}_{\mathrm{WS}}=1 / \mathrm{H}$ & $\mathrm{Z}_{\mathrm{TS}}=\mathrm{Z}_{\mathrm{WS}} \mathrm{V}_{\mathrm{ws}}+\mathrm{Z}_{\mathrm{S}} \mathrm{v}_{\mathrm{ps}}$ \\
& Solids & $\mathrm{Z}_{\mathrm{S}}=\mathrm{Z}_{\mathrm{W}} \rho_{\mathrm{ps}} \mathrm{K}_{\mathrm{oc}} \omega_{\mathrm{ocs}}$ & \\
\hline Fish & Fish & $\mathrm{Z}_{\mathrm{F}}=\mathrm{Z}_{\mathrm{W}} \mathrm{BCF} \rho_{\mathrm{f}}$ & $\mathrm{Z}_{\mathrm{TF}}=\mathrm{Z}_{\mathrm{F}}$ \\
\hline
\end{tabular}

\section{Due to technical limitations, table 2 is only available as a download in the supplemental files section}

\section{Figures}




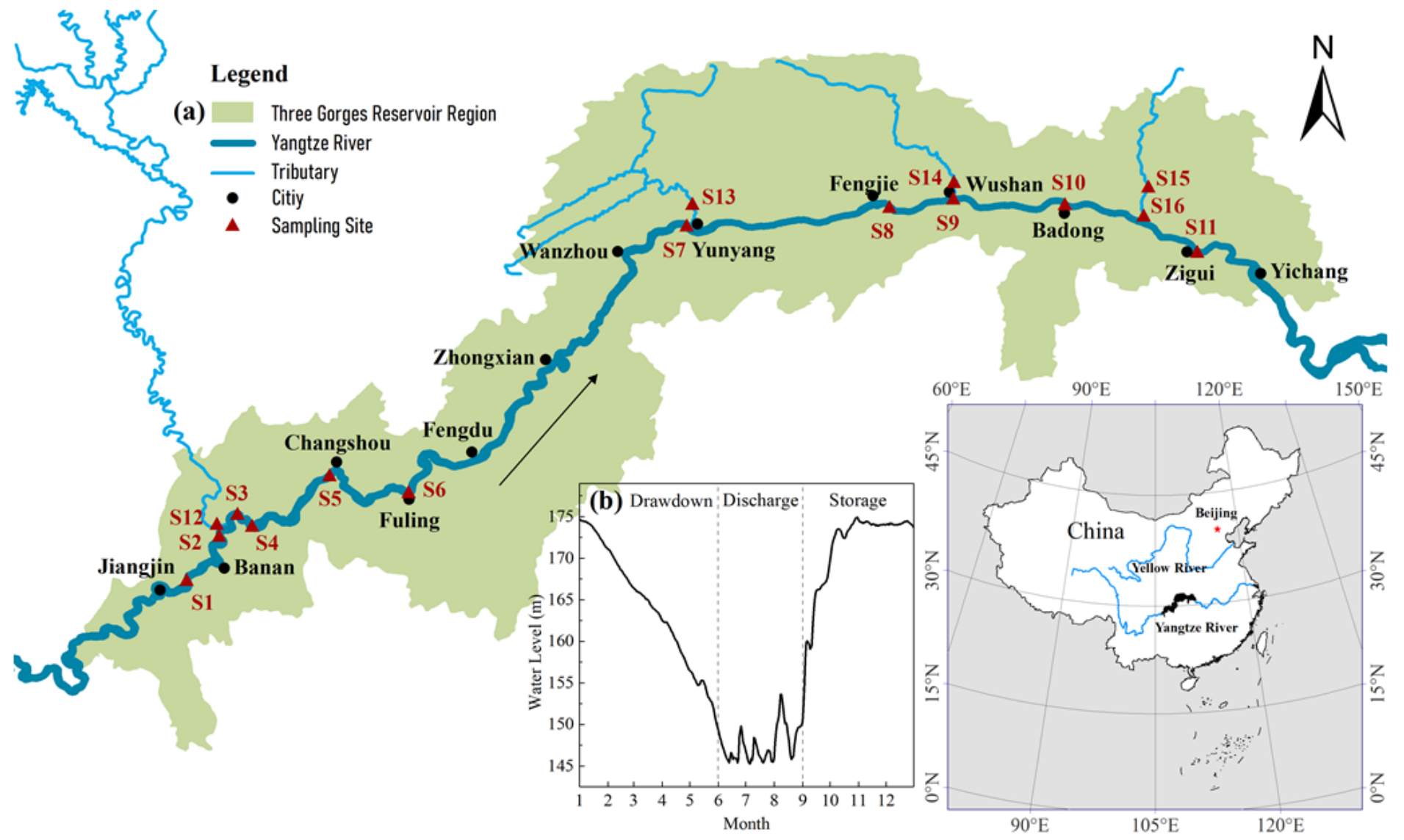

\section{Figure 1}

The study area (a) and the hydrograph in 1 year of the TGR (b) 


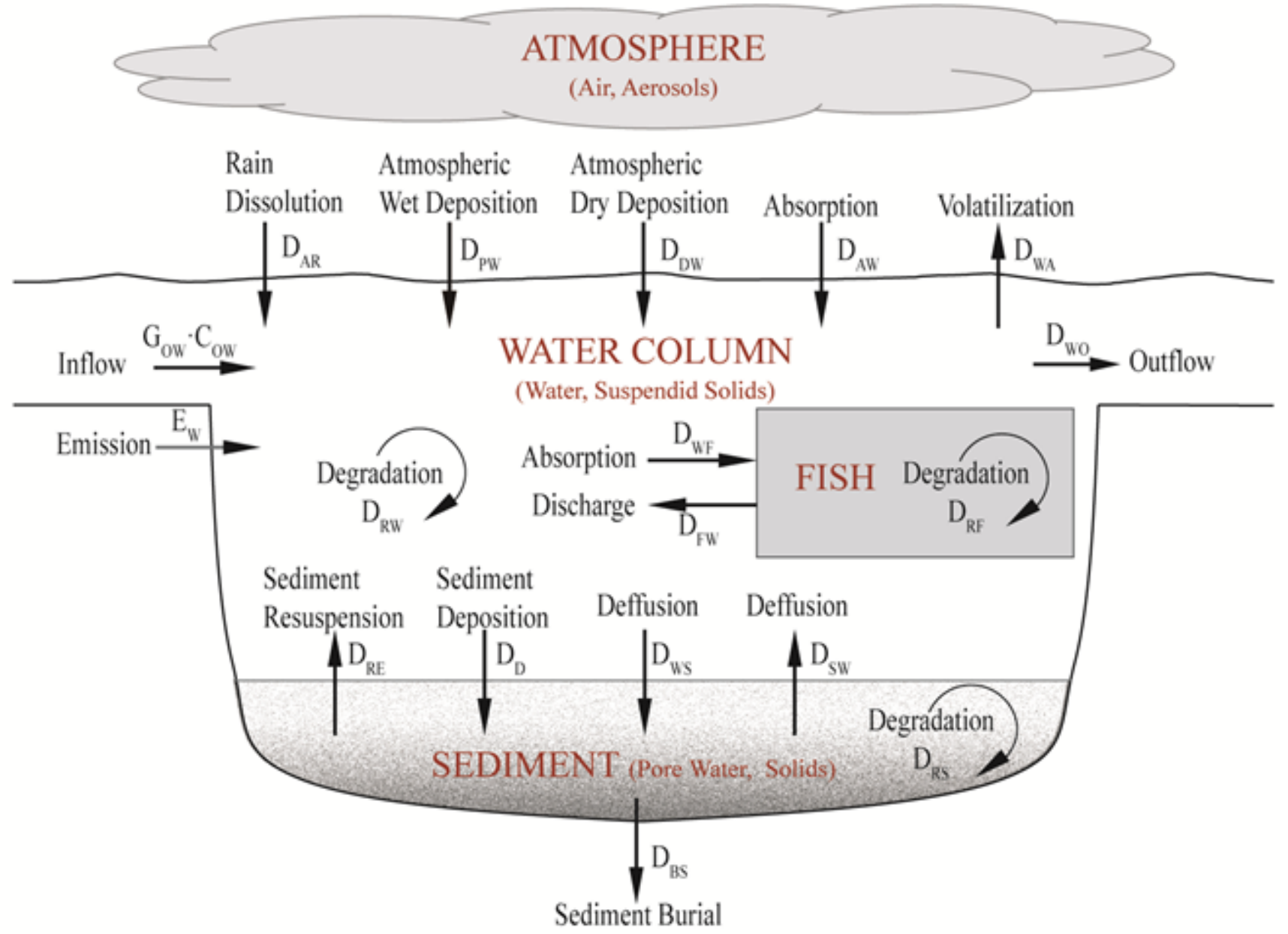

Figure 2

The main processes in the aquatic environment treated in the level IV multimedia fugacity model
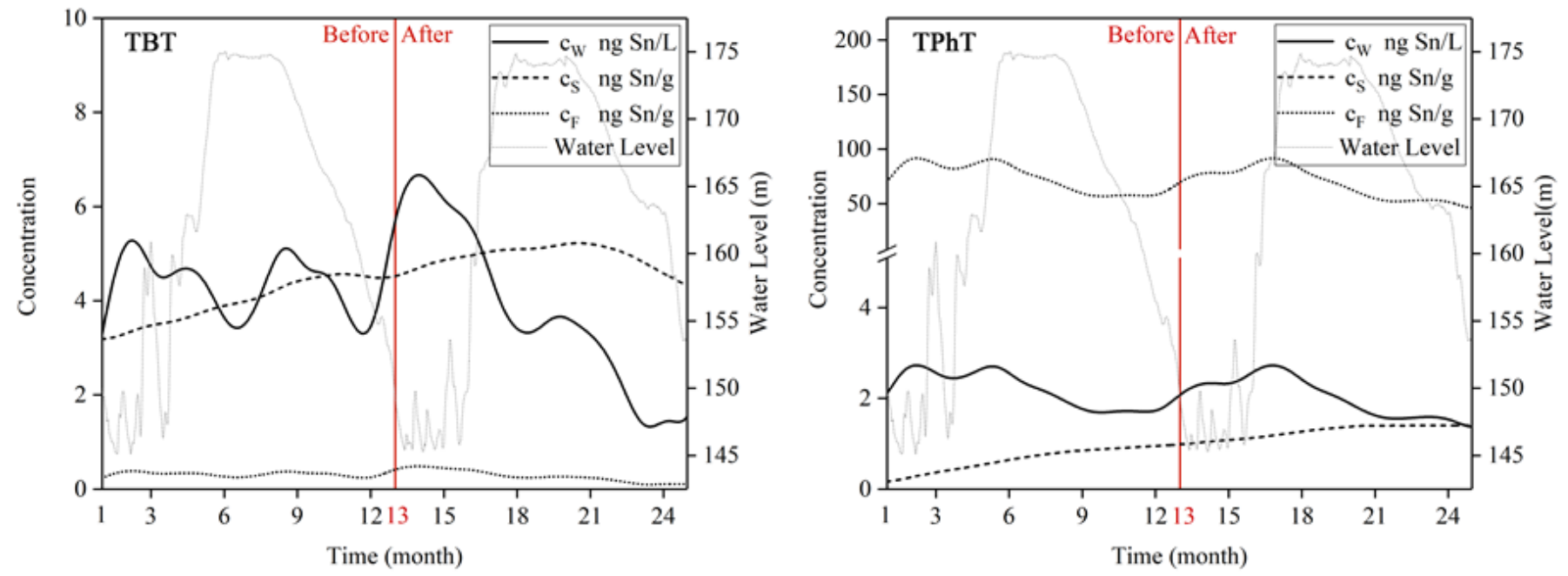

Figure 3 
Variations in the concentrations of TBT and TPhT in different phases during the simulation periods. The concentrations of TBT and TPhT in the atmosphere (CA) are below 10-4 ng Sn/L, which are not shown in the figure.

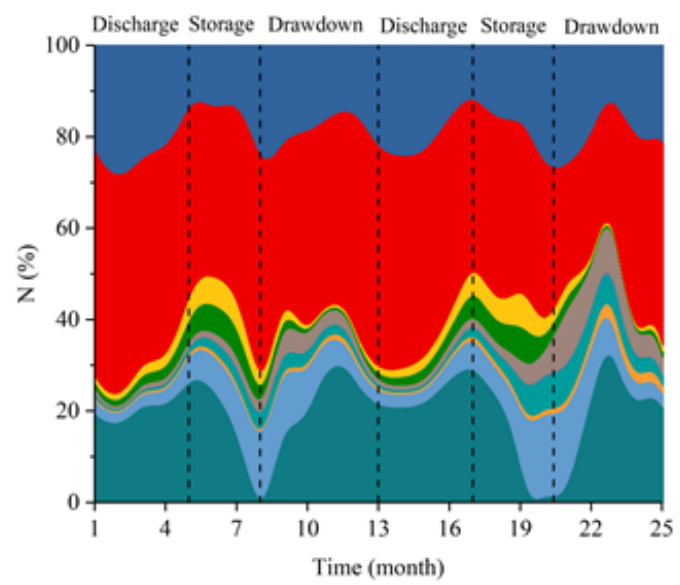

(a) TBT

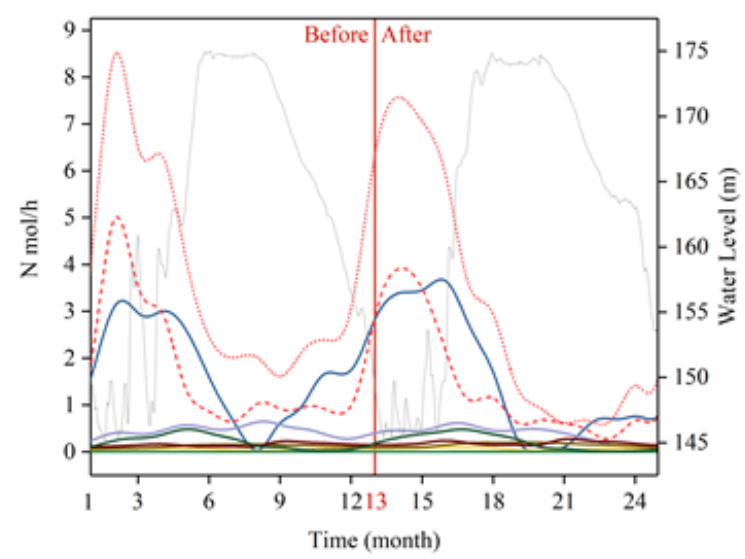

(b) TBT

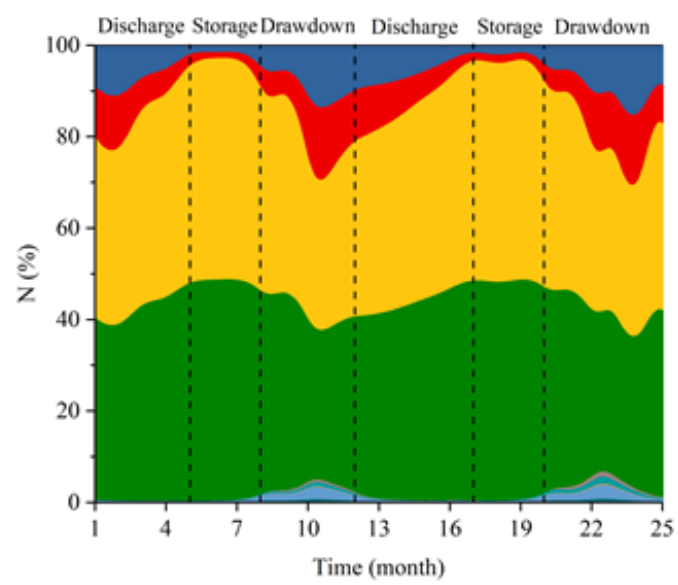

(a) TPhT

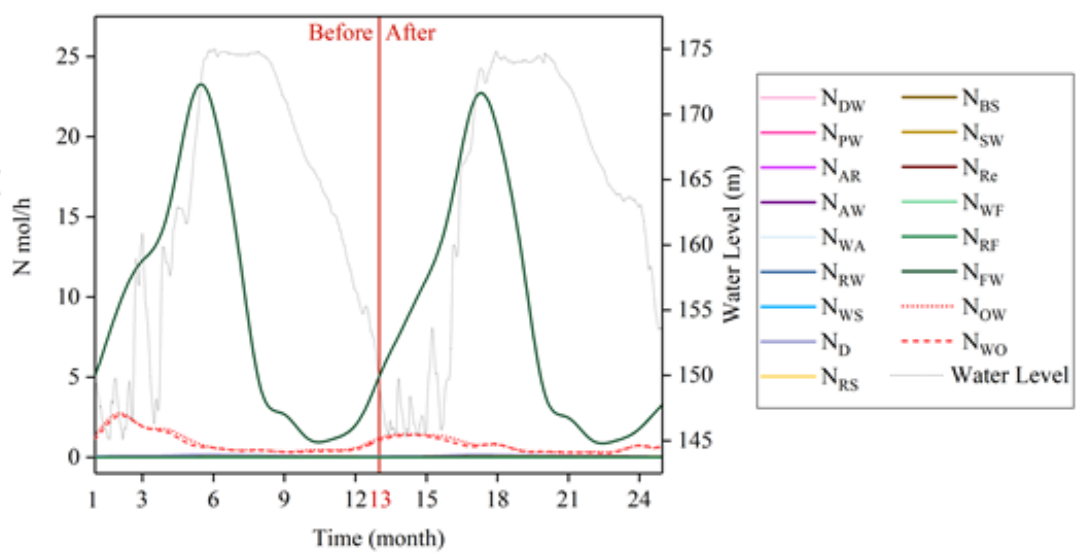

(b) TPhT

\section{Figure 4}

The percentage of transport and transfer fluxes ( $\mathrm{N}$ values, \%) in different periods (a) and the variations of $\mathrm{N}$ values $(\mathrm{mol} / \mathrm{h})$ with water level fluctuations $(\mathrm{b})$ 


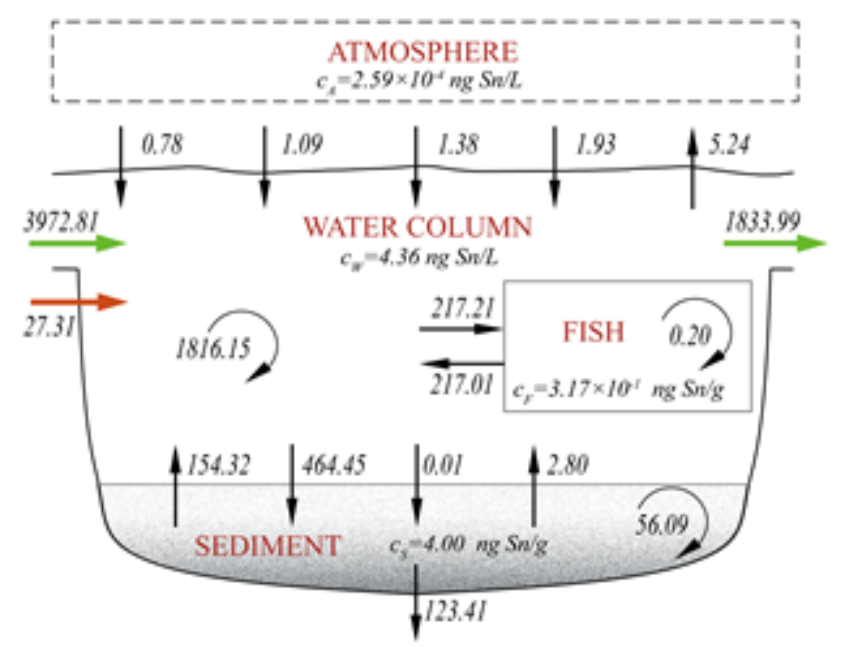

TBT(Before)

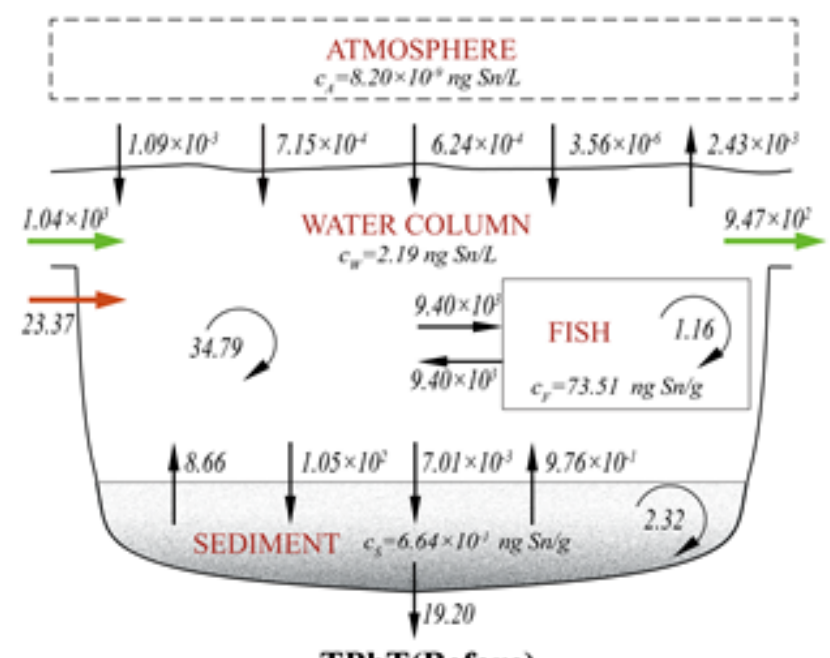

TPhT(Before)

Water Advection $\longrightarrow$ Emission $\longrightarrow$ Interface Transfer
ATMOSPHERE

$c_{4}=2.02 \times 10^{\circ} \mathrm{nz} \mathrm{Su} / \mathrm{l}$
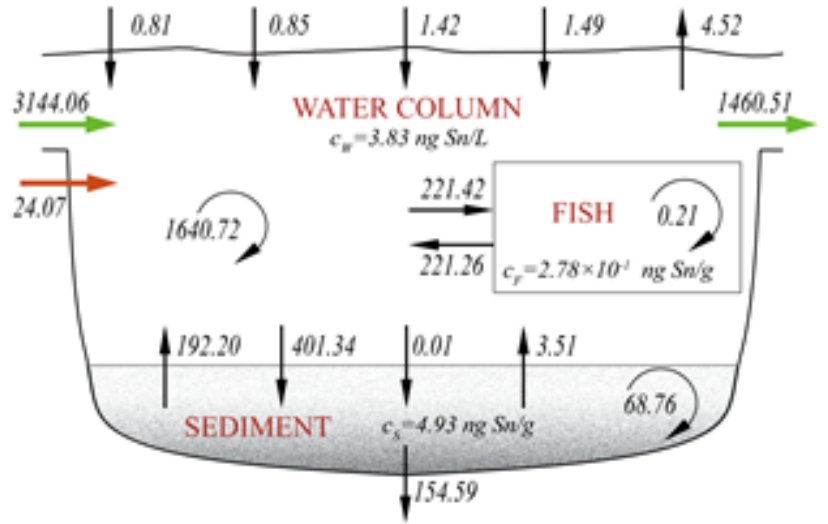

TBT(After)

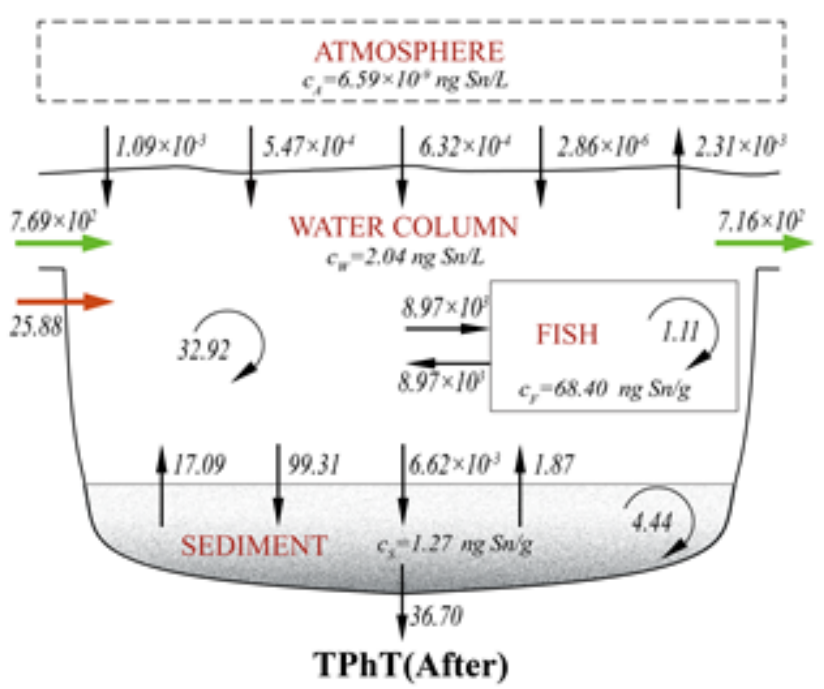

Degradation

Figure 5

The cumulative mass fluxes in the TGR for the year before and after implementation of the AFS Convention 

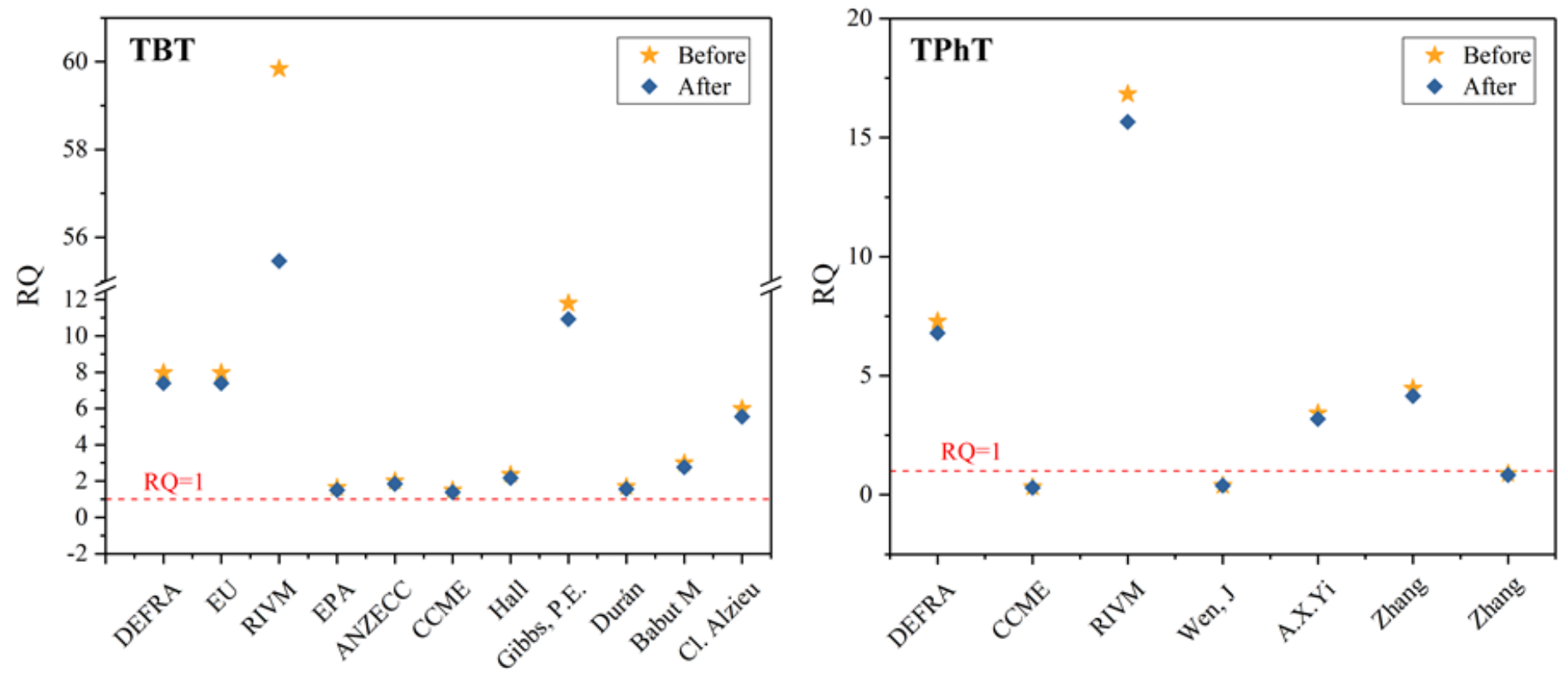

Figure 6

The risk quotient (RQ) values of TBT and TPhT for organisms in the TGR before and after the implementation of the AFS Convention with different water quality criteria and risk thresholds (DERFA, 2017; EU, 2008; RIVM, 2012a, 2012b; USEPA, 2003; ANZECC, 2000; CCME, 1992; Hall et al., 2000; Gibbs, 1987; Duran and Beiras, 2017; Babut et al., 2003;Alzieu, 1998; Wen et al., 2018; Yi et al., 2012; Zhang et al., 2008)

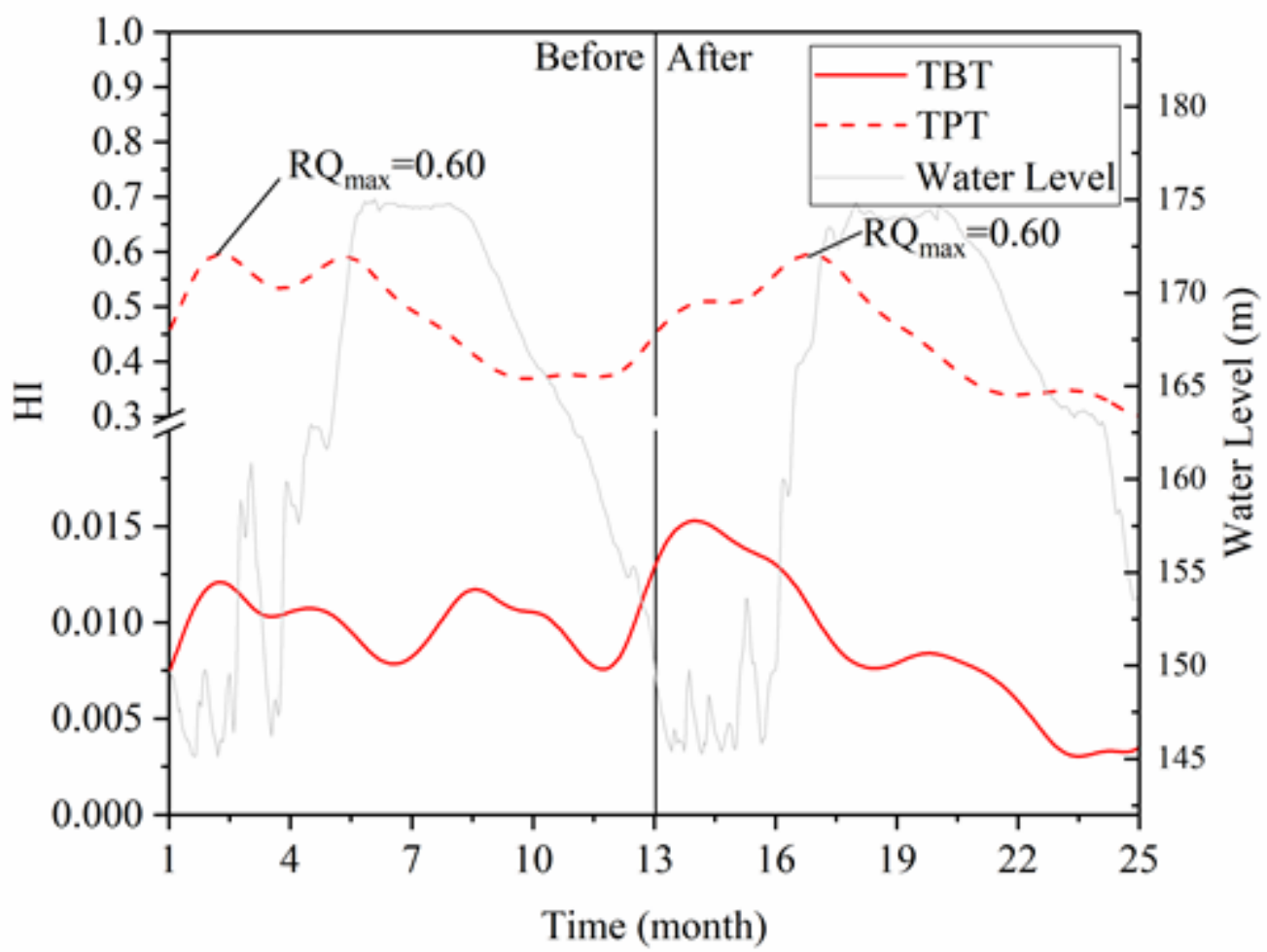


Figure 7

The hazard index $(\mathrm{HI})$ values in the simulation time

\section{Supplementary Files}

This is a list of supplementary files associated with this preprint. Click to download.

- equations1012.docx

- equation9.docx

- equation8.docx

- equation7.docx

- equations56.docx

- Equations14.docx

- equation13.docx

- Supplementarymaterialrevised.docx

- Table2.docx 